\section{Bariatric surgery - An update for the endocrinologist}

\author{
Cirurgia bariátrica - Uma atualização para o endocrinologista
}

Marcio C. Mancini'

\begin{abstract}
Obesity is a major public health problem, is associated with increased rates of mortality risk and of developing several comorbidities, and lessens life expectancy. Bariatric surgery is the most effective treatment for morbidly obese patients, reducing risk of developing new comorbidities, health care utilization and mortality. The establishment of centers of excellence with interdisciplinary staff in bariatric surgery has been reducing operative mortality in the course of time, improving surgical safety and quality. The endocrinologist is part of the interdisciplinary team. The aim of this review is to provide endocrinologists, physicians and health care providers crucial elements of good clinical practice in the management of morbidly obese bariatric surgical candidates. This information includes formal indications and contraindications for bariatric operations, description of usual bariatric and metabolic operations as well as endoscopic treatments, preoperative assessments including psychological, metabolic and cardiorespiratory evaluation and postoperative dietary staged meal progression and nutritional supplementation follow-up with micronutrient deficiencies monitoring, surgical complications, suspension of medications in type 2 diabetic patients, dumping syndrome and hypoglycemia. Arq Bras Endocrinol Metab. 2014;58(9):875-88
\end{abstract}

Keywords

Bariatric surgery; Roux-en-Y gastric bypass; biliopancreatic diversions; obesity; weight loss

\section{RESUMO}

A obesidade é um problema de saúde pública, está associada com aumento do risco de mortalidade e de desenvolver diversas comorbidades e diminui a expectativa de vida. A cirurgia bariátrica é o tratamento mais eficaz para pacientes com obesidade mórbida, reduzindo o desenvolvimento de novas comorbidades, a utilização dos cuidados de saúde e a mortalidade. A criação de centros de excelência com equipes interdisciplinares em cirurgia bariátrica vem reduzindo a mortalidade operatória no decorrer do tempo, melhorando a segurança e a qualidade cirúrgica. $O$ endocrinologista faz parte da equipe interdisciplinar. $O$ objetivo desta revisão é fornecer aos endocrinologistas, médicos e prestadores de cuidados de saúde elementos cruciais de boas práticas clínicas no tratamento de pacientes com obesidade mórbida candidatos à cirurgia bariátrica. Essas informações incluem indicações formais e contraindicações para as operações bariátricas, descrição das operações bariátricas e metabólicas habituais, bem como tratamentos endoscópicos, avaliação pré-operatória, incluindo avaliação cardiorrespiratória psicológica, metabólica e no pós-operatório, dieta com refeições progressivamente estagiadas e seguimento com suplementação nutricional e monitoramento de deficiências de micronutrientes, complicações cirúrgicas, suspensão de medicamentos em pacientes diabéticos tipo 2, síndrome de dumping e hipoglicemia. Arq Bras Endocrinol Metab. 2014;58(9):875-88

\section{Descritores}

Cirurgia bariátrica; bypass gástrico em Y de Roux; desvios biliopancreáticos; obesidade; perda de peso
Obesity \& Metabolic Syndrome Group, Endocrinology \& Metabolism Department, Hospital das Clínicas, Faculty of Medicine, University of São Paulo (HCFMUSP), São Paulo, SP, Brazil
Correspondence to: Marcio C. Mancini Secretaria da Disciplina de Endocrinologia e Metabologia

Av. Dr. Enéas de Carvalho Aguiar, 255, $7^{\circ}$ andar, sala 7037 05403-000 - São Paulo, SP, Brazil mmancini@usp.br

Received on Apr/14/2014 Accepted on Oct/20/2014 DOI: 10.1590/0004-2730000003413 


\section{INTRODUCTION}

$\mathrm{O}$ besity is a major public health problem (1). The past three decades have seen an astonishing increase in obesity rates, and it is usually assumed that environmental changes are the main causes, although genetic bases can undoubtedly be involved (2). In 2008, according to the World Health Organization, 1.4 billion adults were overweight and 500 million adults worldwide were obese. It has been projected that $2 / 3$ of the world's population could be overweight $(2.2 / 3.3$ billion) or obese ( $1.1 / 3.3$ billion) by 2030 (2). Obesity is common and is associated with increased rates of mortality and morbidity $(3,4)$. Excess weight radically elevates an individual's risk of developing a quantity of non-communicable diseases, such as type 2 diabetes, hypertension, dyslipidemia, sleep apnea, non-alcoholic steatohepatitis, stroke, cancer, coronary heart disease, osteoarthritis, gallbladder disease, as well as respiratory complications, infertility, reduced quality of life and psychological difficulties (3-5). Obesity appears to lessen life expectancy markedly, especially among individuals in younger age groups adults (6), and the lifetime of morbidly obese subjects is decreased by an estimated 5-20 years depending on gender, age and race $(1,7)$.

Bariatric surgery has demonstrated to be the most effective method of treatment of the morbidly obese patients $(1,7,8)$. The long-term studies provide evidence of substantial reduction in: risk of developing new comorbidities, health care utilization and mortality in bariatric surgery subjects $(7,9,10)$. Bariatric operations are a recognized and fundamental part in the treatment of morbid obesity $(7,8)$. The aim of this review is to provide endocrinologists, physicians and health care providers crucial elements of good clinical practice in the management of morbidly obese patients. Standard search strategy was used to retrieve international journal articles from PubMed database within the last 10 years. The interventions of interest were bariatric operations and the outcomes were improvement in comorbidities, weight loss and adverse effects.

\section{PREOPERATIVE PHASE}

The interdisciplinary team consists of the following specialists experienced in obesity management and bariatric surgery: endocrinologist or specialized physician, bariatric surgeon, nutritionist, psychiatrist or psycholo- gist, anesthetist, nurse, social worker (11). The bariatric procedures should be done at interdisciplinary obesity management centers with properly qualified staff and adequate equipment. The bariatric surgeon's skill is a crucial issue. It is not prudent to practice bariatric techniques on a sporadic basis (12).

The formal indications for bariatric operations are: 1) patients in age groups from 18 years to 65 years (in some guidelines the limit is 60 years) (11). Over 65 years, a specific evaluation considering surgical and anesthetic risk, presence of co-morbidities, life expectancy, benefits of weight loss, and age-limitations such as esophagic dismotility and osteoposoris. In elderly patients the objective of the operation is mainly to improve quality of life (8). 2) Body mass index (BMI) greater than or equal to $40 \mathrm{~kg} / \mathrm{m}^{2}$ or $35 \mathrm{~kg} / \mathrm{m}^{2}$ with one or more severe obese related co-morbidities (in which surgically induced weight loss is likely to improve the condition). 3) The patients should have failed to lose weight or to maintain weight loss despite appropriate medical care (11).

In the 2013 AACE, TOS, and ASMBS Medical Guidelines for Clinical Practice for the Perioperative Nutritional, Metabolic, and Nonsurgical Support of the Bariatric Surgery Patient (2013 AACE-TOS-ASMBS $\mathrm{CPG}$ ) among these more severe obesity-related comorbidities were included type 2 diabetes, hypertension, hyperlipidemia, obstructive sleep apnea (OSA), obesity-hypoventilation syndrome (OHS), Pickwickian syndrome (a combination of OSA and OHS), nonalcoholic fatty liver disease (NAFLD) or nonalcoholic steatohepatitis (NASH), pseudotumor cerebri, gastroesophageal reflux disease (GERD), asthma, venous stasis disease, severe urinary incontinence, debilitating arthritis, and considerably impaired quality of life, also could be included among debilitating conditions allowing to be offered a bariatric procedure (13). In the 2013 CPG, patients with BMI of $30-34.9 \mathrm{~kg} / \mathrm{m}^{2}$ with diabetes or metabolic syndrome were also included to be offered a bariatric procedure, although current evidence is limited by the number of subjects studied and lack of long term data demonstrating net benefit. This new position in the 2013 Guidelines has emerged because it has become hugely ostensible that bariatric surgery exerts a robust and beneficial effect on type 2 diabetes, leading to high rates of remission and reduction in diabetes-related deaths. Further, the mechanisms that lead to the improvement of type 2 diabetes seem to be not fully dependent of the reduction of food intake and 
bodyweight (e.g., reduction in ghrelin levels, increase in adiponectin and glucagon-like peptide-1 levels) (13). The International Diabetes Federation allows bariatric surgery acceptable for subjects with a BMI greater than or equal to $30 \mathrm{~kg} / \mathrm{m}^{2}$ and type 2 diabetes who have failed to respond accordingly to lifestyle modifications and at least two oral antidiabetic medications (14).

In some countries (like Brazil) the patient should have be in the BMI greater than or equal to 35 or 40 for at least two years (except if a severe co-morbidity is present or if BMI is greater than or equal to 50) (15). Surgery is guaranteed in patients who had a previous BMI above the limit, exhibited a considerable weight loss in a medical therapy, but are below the minimum indication weight for surgery (11).

Recently the inferior limit in Brazil was lowered from 18 to 16 years if the Z-score BMI is greater than or equal +4 and the epiphyseal growth plate is already closed when there is an agreement between the legal guardian and the multidisciplinary team. Below 16 years of age, an ethical committee must be consulted after cautious attention, in exceptional cases such as genetic syndromes (e.g. Prader-Willi) $(15,16)$.

The main contraindications for bariatric surgery are the absence of clinical treatment or management, the existence of active non-stabilized psychiatric illnesses such as major depression and psychotic disorders, alcohol and/or drug active dependencies, diseases threatening life in the short term, and patients incapable to care for themselves without family or social support (11).

In the preoperative phase, it is of crucial importance to evaluate the patient motivation and disposition to adhere to follow-up programs, certifying that the patient is entirely informed on the benefits and risks of the surgical choices and also the need of lifetime follow-up, as well as the likely limited results of the operations. In this context, the evaluation should include a psychological and social examination to assess expectation and motivation, and also life conditions and social support network (11).

It is also important to clarify the dietary, behavioral and lifestyle changes mandatory after the operation. Depending on the scheduled procedure and clinical status of the patient, the patient should undertake additional assessment for metabolic and endocrine disorders, sleep apnea and cardiopulmonary function, gastroesophagic disorders, bone density and bone composition (11). The presence of eating pathologies such as binge eat- ing disorder (BED) increase the risk of lower weight loss and weight regain after bariatric surgery (11) and also of developing other eating disorder patterns such as post-surgical refusal to eat (17).

\section{OPERATIONS TECHNIQUES}

The usual bariatric and metabolic operations that are presently offered for patients needing weight loss and/ or metabolic control are: adjustable gastric banding (AGB), sleeve gastrectomy (SG), Roux-en-Y gastric bypass (RYGB), biliopancreatic diversion/Scopinaro (BPD-S) and BPD/duodenal switch (BPD-DS) (Figure 1$)$. At this time, there is still insufficient evidence to generalize in favor of one bariatric surgical procedure for the morbidly obese population. Physicians should exercise caution when recommending BPD-S, BPD-DS, or related procedures because of the greater associated nutritional risks related to the increased length of bypassed small intestine. A laparoscopic procedure should be considered as the desirable method to the operation in bariatric surgery, as long as no contraindications for the laparoscopic approach exist. The most common performed procedures in Brazil are RYGB and SG. AGB is less performed nowadays due to weight regain and less weight loss and BPD due to nutritional risks (13).

The RYGB comprises the construction of a small gastric pouch that is then connected to a distal segment of small intestine (alimentary limb, length $\sim 100 \mathrm{~cm}$ ). The remnant of the stomach is left in situ but is disconnected from the food stream. It reconnects with the alimentary limb at the jejuno jejuno anastomosis (biliopancreatic or digestive limb, length $\sim 60 \mathrm{~cm}$ ). The restrictive component is based on the small pouch as well as the narrow aperture connecting the gastric pouch to the jejunum. The RYGB can be performed placing a band above the gastro jejuno anastomosis (banded gastric bypass) to restrict the inside width to around one centimeter, although most surgeons do not use this procedure. The malabsortive component is marginal at best. Early complications associated to the procedure are reported to be leakage, bleeding pulmonary embolus, and gastrojejunal strictures and late complications include internal hernias, ulcers, vitamin deficiencies, and anemia $(12,13)$ (Figure 1).

The SG involves removing $80 \%$ of the stomach, leaving behind only a "sleeve" of the stomach (18) (Figure 1). 
The AGB is placed around the top portion of the stomach to reduce stomach size restricting the volume of ingested solid food. The band itself is made of silicone and is connected via plastic tubing to a port implanted in the abdominal wall. The quantity of fluid injected into the port gradually increases the restriction on the stomach. Patients must have frequent followups with their physicians to titrate the volume placed into the port. No alteration of the anatomy is required, and thus the procedure is completely reversible. The mortality is $0.05 \%$. Complications include band erosions, esophageal dilatation, port infections, band slips, reoperations and port problems (13) (Figure 1).
BPD-S is a malabsortive procedure is which a distal gastrectomy and a Roux-en-Y configuration are created with a short common limb. The alimentary limb is $250 \mathrm{~cm}$ length and the common limb is only $50 \mathrm{~cm}$. The stomach links straight to the ileum. The duodenal switch (BPD-DS) procedure is similar to the Scopinaro technique, but the gastrectomy is vertical, not distal, a duodenoileal anastomosis is performed to enhance absorption of minerals, to preserve the pilorum and the common limb is a little bit longer $(75-100 \mathrm{~cm})$. BPD can cause significant complications, such as hypovitaminosis, hypoalbuminemia, severe metabolic bone disease, and cirrhosis (13) (Figure 1).
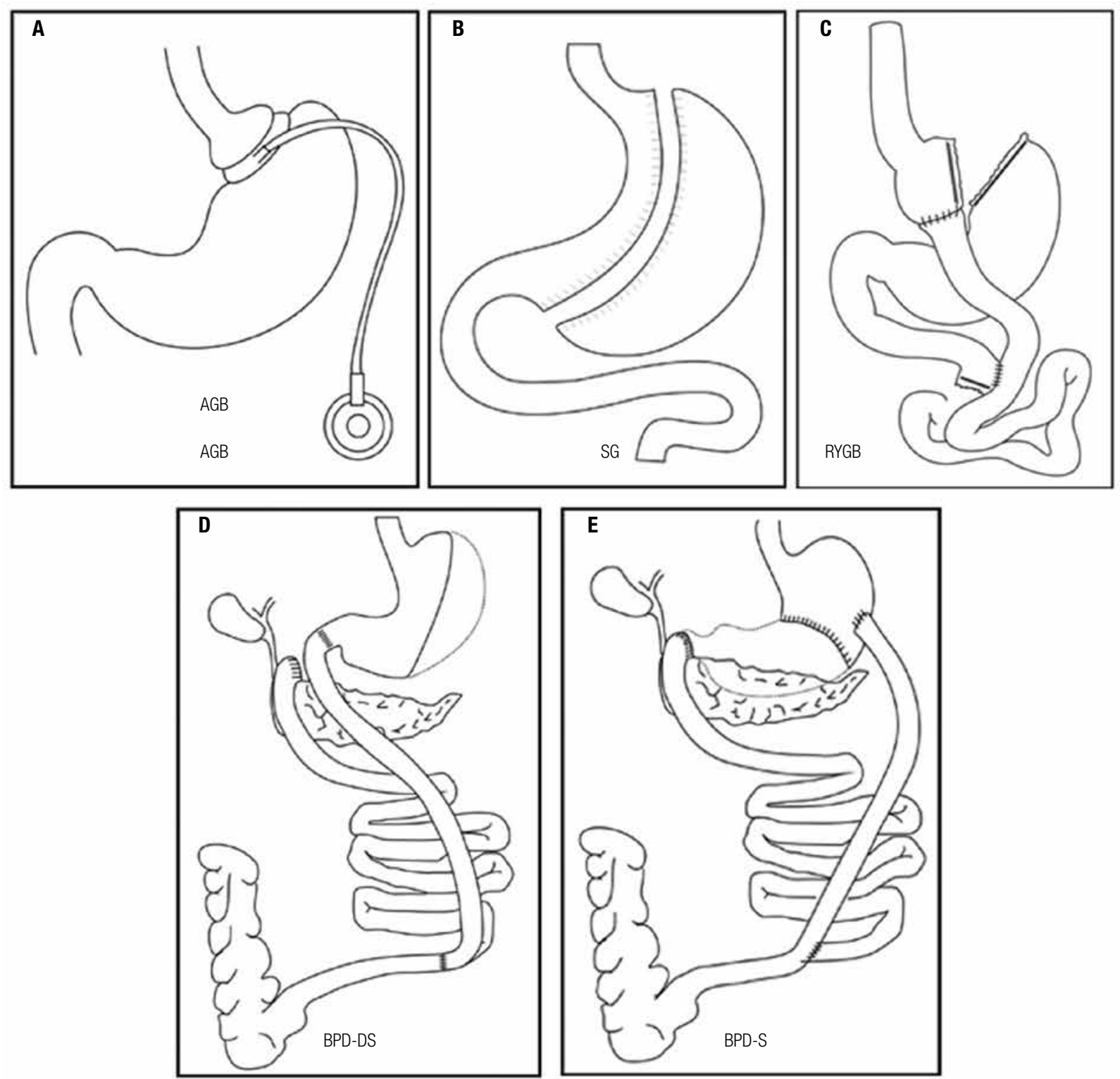

Figure 1. Usual bariatricoperations: (A) adjustable gastric banding (AGB), (B) sleeve gastrectomy (SG), (C) Roux-en-Y gastric bypass (RYGB), (D) BPD/ duodenal switch (BPD-DS), and (E) biliopancreatic diversion/Scopinaro (BPD-S). 
Other surgical techniques have been proposed as bariatric and/or metabolic procedures: duodenojejunal bypass (sleeve gastrectomy with alimentary limb of 150 $\mathrm{cm}$ and biliopancreatic limb of $100 \mathrm{~cm}$ ), omentectomy, ileal interposition with sleeve gastrectomy, sleeve gastrectomy with omentectomy and jejunectomy, bipartition of the gastintestinal transit (ileus brought directly to the stomach without occluding the duodenum and an anastomosis between the jejunum and ileum below brings the segments together again). Although some of these procedures are highly promising, they are currently considered experimental (19).

Intragastric balloon treatment is an endoscopic treatment. The balloon is placed inside the stomach for six months and inflated with saline solution, promoting a weight loss of $5-9 \mathrm{~kg} / \mathrm{m}^{2}$ with improvement of obesity-related comorbidities. A regain of weight in a 1 -year follow-up period of $25-40 \%$ and a failure rate of $15 \%$ in studies that defined a successful weight loss have to be considered. Gastrointestinal complications, mainly esophagitis, nausea and vomiting were present in more than $5 \%$ of patients, leading to intolerance and resulting in its removal in $7 \%$. Balloons deflated in $8 \%$, and some of these patients had to be operated. Intragastric balloon treatment can be a valuable method in selected patients, such as super obese patients preoperatively who need to lose weight to minimize risks before undergoing bariatric surgery, but nonresponse, intolerance and weight regain have to be taken into account $(20)$.

With the concept that the exclusion of the proximal segment of the small intestine (biliopancreatic limb of RYGB), an endoscopic single, minimally invasive device for temporary duodenal exclusion (EndoBarrier) was developed, consisting of a metal anchoring system with tiny hooks and a sleeve made of a polymer about $60 \mathrm{~cm}$ long which prevents contact of food with the biliary and pancreatic secretions until the initial segment of the jejunum (Figure 2). This device, which has been studied for up to one year in obese diabetic patients by our group in the Hospital das Clínicas, was effective in reducing weight, hemoglobin Alc and weight control in type 2 diabetes (2l) and is already being used in several European countries and Chile (in Brazil is in process of scrutiny by National Health Surveillance Agency - Anvisa). Possible mechanisms of action include malabsorption of calories, abnormal gastrointestinal motility and modulation of gastrointestinal neurohormonal signaling $(21,22)$.
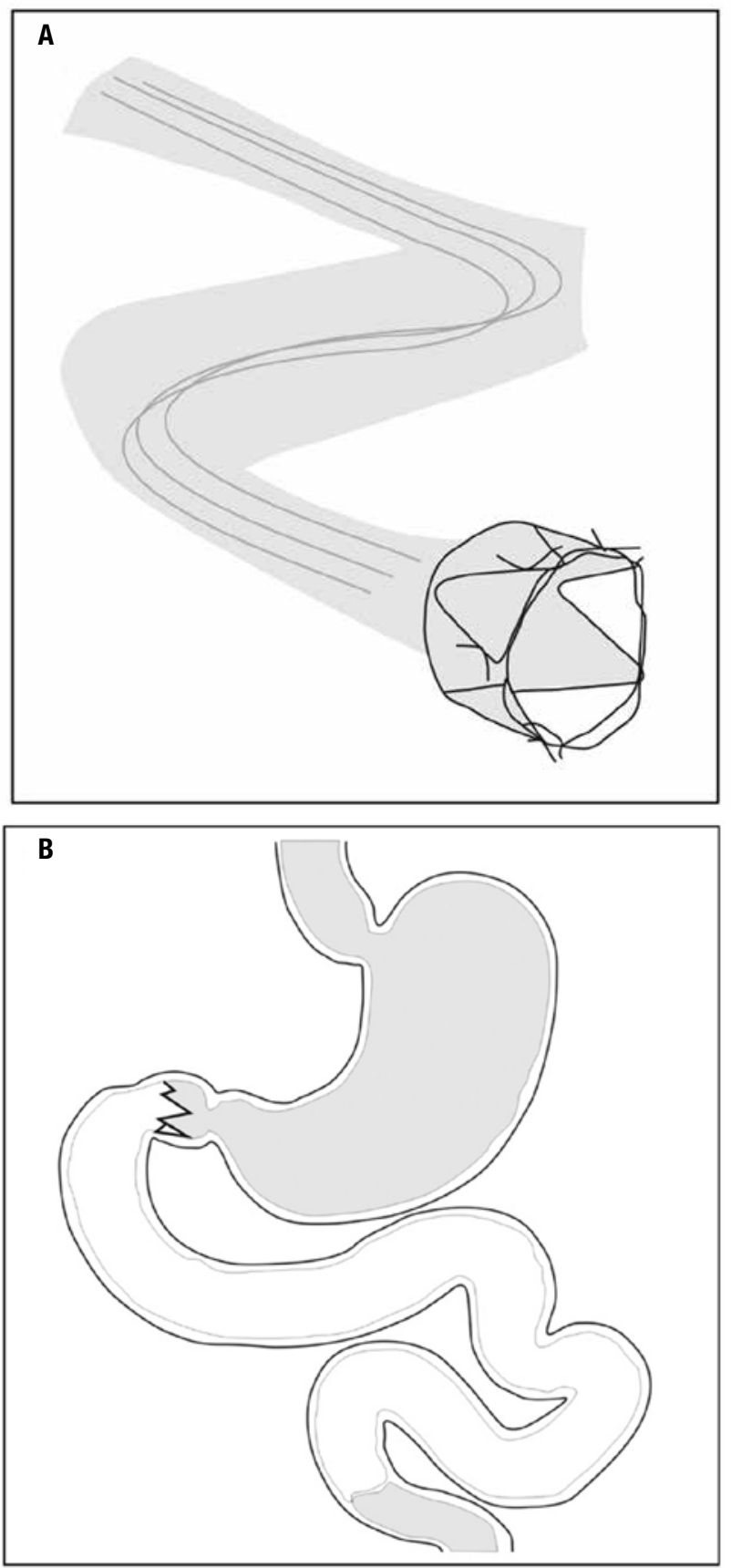

Figure 2. Endoscopic device for temporary duodenal exclusion (EndoBarrier) consisting of a metal anchoring system with tiny hooks and a sleeve made of a polymer $60 \mathrm{~cm}$ long $(\mathrm{A})$ which prevents contact of food with the biliary and pancreatic secretions until the initial part of the jejunum (B).

\section{PREOPERATIVE EVALUATION AND POSTOPERATIVE IMMEDIATE FOLLOW-UP}

Morbid obesity is a permanent illness. The treating physician is in charge for the follow-up not only before, but mainly after the operation. Reasonably, the treatment outcome is significantly reliant on, among other factors, on patient agreement with long-term follow-up. 
The patients should be instructed on the overall importance of the intake of adequate quantity of protein to avoid disproportionate lean body mass loss, avoidance of ingestion of intense sweets to prevent dumping syndrome, particularly after RYGB, and better use of crushed and/or rapid release medication. Type 2 diabetic (T2DM) patients, should have anti-diabetic medication and/or insulin adjusted with no delays post-operatively in order to minimize risks of hypoglycaemia. Most patients can have the medications suspended during the first or second post-operative days. The criteria for assessment of the effect of bariatric surgery on remission of T2DM are summarized in table 1 (11).

Table 1. The criteria for assessment of the effect of bariatric surgery on remission of type 2 diabetes mellitus (1)

\begin{tabular}{lccc}
\hline & $\begin{array}{c}\text { Partial } \\
\text { remission }\end{array}$ & $\begin{array}{c}\text { Complete } \\
\text { remission }\end{array}$ & $\begin{array}{c}\text { Prolonged } \\
\text { remission }\end{array}$ \\
\hline Fasting blood glucose & $100-125 \mathrm{mg} / \mathrm{dL}$ & $<100 \mathrm{mg} / \mathrm{dL}$ & $<100 \mathrm{mg} / \mathrm{dL}$ \\
$\mathrm{HbA1C}$ & $\begin{array}{c}>6 \% \text {, but } \\
<6.5 \%\end{array}$ & $<6 \%$ & $<6 \%$ \\
& At least 1-year & At least 1-year & At least 5-year \\
$\begin{array}{l}\text { No active } \\
\text { pharmacologic } \\
\text { therapy or } \\
\text { procedures }\end{array}$ & & & \\
\hline
\end{tabular}

RYGB surgery is associated with durable remission of T2M (23) in many but not all severely obese diabetic adults and about one third experiences a relapse within 5 years of initial remission. The median duration of remission was 8.3 years. Significant predictors of complete remission and relapse were poor preoperative glycemic control, insulin use, and longer diabetes duration. Weight trajectories after surgery were significantly different for never remitters, relapsers, and durable remitters (24). Failure of resolution of the diabetes can also result from lack of patient compliance, inadequate weight loss, longstanding uncontrolled diabetes, or when the diabetes is actually a latent autoimune diabetes of the adult (LADA) or a type $1(25)$.

Other criteria were suggested for the evaluation of the influence of bariatric surgery on optimization of metabolic status of some other co-morbid situations, for instance, total cholesterol $<4 \mathrm{mmol} / \mathrm{l}(<154.67 \mathrm{mg} /$ $\mathrm{dL})$, LDL-cholesterol $<2 \mathrm{mmol} / \mathrm{l}(<77.34 \mathrm{mg} / \mathrm{dL})$, triglycerides $<2.2 \mathrm{mmol} / \mathrm{l}(194.86 \mathrm{mg} / \mathrm{dL})$, blood pressure $<135 / 85 \mathrm{mmHg}$, > 15\% weight loss, or lowering of HbAlc by $>20 \%$ (11).

Women candidates for bariatric surgery should avoid pregnancy in the preparatory period and for at least 12 to 18 months postoperatively. Women who become pregnant after bariatric operations should be correctly recommended and supervised for suitable weight gain, dietary, nutritional supplementation, and fetal conditions. Pregnancies post-LAGB should have band adjustments if necessary. Laboratory screenings should include iron folate, vitamin B12, calcium and fat soluble vitamins every trimester. Women after RYGB, BPD-S or BPD-DS should be counseled on non-oral contraceptive choices (13). To detect gestational diabetes, alternative paths like fasting and $2 \mathrm{~h}$ postprandial glycaemia have to be used after RYGB, BPD-S or BPD-DS or if the patient reports dumping complications. Women with polycystic ovary syndrome should be firmly counseled that their fertility status might be improved postoperatively. Estrogen replacement should be discontinued for at least three weeks before bariatric surgery to reduce the risks for postoperative thromboembolic phenomena (26).

Noninvasive cardiac testing is determined on the basis of the individual risk factors and findings on history and physical examination. If the patient has an active potentially unstable or unstable cardiac condition (that dramatically increase the risk of cardiac morbidity and mortality) such as unstable coronary syndromes (unstable or severe [class III or IV] angina, recent myocardial infarction [less than 30 days]), decompensated heart failure (New York Hear Association class IV or worsening or new onset heart failure), significant arrhythmias (atrioventricular block [AVB] of high grade, $3^{\text {rd }}$ degree AVB; known recently symptomatic bradycardia, ventricular tachycardia, symptomatic ventricular arrhythmia, supraventricular arrhythmias (including atrial fibrillation) with rapid ventricular response (heart rate $>100 \mathrm{bpm}$ ); severe valvular disease (severe aortic stenosis, symptomatic mitral stenosis). In the presence of some of these active cardiac conditions, the patient should be referred to a cardiologist to assess the need for correction of the condition before the proposed surgical procedure (27).

By the way, if there is no active cardiac condition, we can proceed with the evaluation. Then, we should assess the functional capacity of the patients. In most of the cases, the determination of the functional capacity of the patients can be performed by simple and worthy questions. A patient who cannot perform his daily activities (dressing, bathing alone) because of cardiac symptoms obviously has a low functional capacity. The patient who can play a game of football or swim- 
ming practice has a great functional capacity. In a very practical way Freeman \& Gibbons suggest two simple questions to determine the functional capacity of the individual: "Do you walk four blocks without stopping for limiting symptoms?" and "Are you able to climb two flights of stairs without stopping for limiting symptoms?" The affirmative answers to these questions confirm adequate functional capacity for patients, freeing the patient to surgery without further investigation. These activities correspond to an exercise tolerance of 4-5 metabolic equivalents (METs), which is typically equivalent to the physiological stress of most non cardiac surgery requiring general anesthesia. On the other hand, in the negative of these issues can confirm poor functional capacity and improved clinical investigation of the patient response is required. However, when evaluating obese individuals, particularly those with morbid obesity, it is very difficult to predict the functional capacity only through clinical history. The presence of pulmonary disease, osteoarthritis and poor physical conditioning make evaluation of cardiovascular symptoms quite difficult $(27,28)$.

Frequently, it can be impossible to assess the functional capacity of the patient. Then, we evaluate the cardiac risk index. The following conditions are considered situations of increased cardiac risk: history of ischemic heart disease (prior myocardial infarction, prior positive stress test; typical angina, $\mathrm{Q}$ waves on the ECG; angioplasty, use of nitrates), history of congestive heart failure, past of acute pulmonary edema, presence of B3; crackles in both lung bases; evidence of heart failure on a chest radiograph; history of prior cerebrovascular disease; diabetes mellitus for more than five years, evidence of microvascular complications; renal impairment (creatinine $>2 \mathrm{mg} / \mathrm{dL}$ ), multiple cardiovascular risk factors (three or more of the following conditions: hypertension, high LDL, decreased HDL, smoking, glucose intolerance or diabetes) (27).

If the patient has not any of these six indicators of cardiac risk, he may proceed with the planned operation, without further cardiac testing. In these cases, the anticipated risk of perioperative cardiac events is approximately $0.5 \%$. It is generally agreed that beta-blockers should be continued in patients who undergo surgery and who have used the therapy to treat angina, arrhythmias, and hypertension. Interruption of beta-blockers in some patients can lead to recurrent angina, rebound hypertension and atrial fibrillation in postoperative period when the patient is particularly vulnerable to an additional physiological stress. Patients who previously were not in use of beta-blockers and feature two conditions of increased cardiac risk may benefit from the use of this medication. In the presence of three or more risk factors the use of beta-blockers aiming at reducing heart rate is mandatory. The dose should be titrated individually, aiming to become a resting heart rate $<65 \mathrm{bpm}$. The dose increase should be gradual and this should be done at least one month before the procedure. The patient should be followed closely in the perioperative period to avoid the use of excessive doses, since inadequate doses are associated with symptomatic hypotension and bradycardia. The POISE study (Perioperative Ischemic Evaluation) where the blocker was started immediately before non cardiac surgery caused an increase in hypotension and bradyarrhythmia, and higher mortality at 30 days postoperatively. Therefore, a gradual titration is essential in the preoperative period for the benefit of beta-blocker (29).

Regarding non-invasive cardiac testing, they should only be considered if the test result has the potential to modify the conduct. As the blocker will be established in patients with increased cardiac risk, the rationale for the non-invasive test is to find out which patients should undergo a procedure of coronary revascularization before bariatric surgery. The objective of the preoperative evaluation is to minimize the risks precipitated by surgery and not necessarily accurately diagnose the heart condition. Consequently, non-invasive tests would be limited to a small number of circumstances, such as a patient with previous myocardial infarction, stable angina and low functional capacity. Non-invasive cardiac tests most commonly used include echocardiography or myocardial perfusion study, both after exercise or pharmacological stress. The exercise tests are limited in large obese because of their weight or orthopedic problems. In these situations it is preferable to use pharmacological stress. The choice will depend on the test and availability service experience. Obesity can reduce the accuracy of perfusion test with thallium-201 or technetium-99. Attenuation correction is needed to improve specificity in patients with BMI $>30 \mathrm{~kg} / \mathrm{m}^{2}$. Stress echocardiography may have the quality of the image limited due to obesity. The use of transesophageal technique offers superior image quality, but its safety has been questioned in obese patients. Few studies conducted evaluation of preoperative risk using transesophageal echocardiography stress in morbidly obese patients (30). Those with positive findings on non-invasive tests should be re- 
ferred to a cardiologist, who then analyzes the need for angiography and/or coronary revascularization before the operation $(27,28)$.

In the respiratory system assessment, it is important to recognize the following conditions: lung diseases associated with obesity (such as obstructive sleep apnea syndrome [OSAS] and obesity hypoventilation syndrome [OHS]) and intrinsic lung diseases that may be aggravated by obesity (such as chronic obstructive pulmonary disease, asthma, pulmonary fibrosis, pulmonary hypertension and chronic pulmonary embolism). Abdominal obesity causes reduced lung volumes, reduces chest wall compliance and increases the total demand of the body for oxygen. Moreover, obesityrelated diseases such as type 2 diabetes, may lead to neuropathic and vascular damage, compromising the function of the respiratory muscles and pharyngeal dilator muscles. In OHS, patients have a restrictive pattern in the evaluation of pulmonary function due to decreased compliance of the chest wall. The most common is a reduction in total lung capacity as a result of reduced expiratory residual volume and functional residual volume, leading to an abnormal distribution of ventilation and worsening of gas exchange. Added to this, there is a limitation of the expiratory flow, with an increased work of diaphragmatic muscles. Patients with OHS are at increased risk because of the greater severity of clinical manifestations. These patients, therefore, should be carefully evaluated before surgery (31).

The most common respiratory disease associated with obesity is OSAS. Obesity can predispose to OSAS due to the accumulation of fat around the oropharynx and the muscles of the pharynx, changing the geometry of the airways, resulting in increased extraluminal pressure and prone to collapse. The measurement of the neck circumference is an imperative anthropometric measure and may be adjusted according to the presence of other symptoms and signs (Table 2). The assessment of daytime sleepiness can be done using the Epworth Sleepiness Scale (ESS) (32) (Table 3). The Berlin questionnaire is another mean to identify patients with OSAS (33).

Less common, but probably underdiagnosed is the OHS, defined as the development of hypercapnia $\left(\mathrm{PaCO}_{2}>45 \mathrm{mmHg}\right)$ during wakefulness in obese individuals $\left(\mathrm{BMI}>30 \mathrm{~kg} / \mathrm{m}^{2}\right)$ in the absence of other reasons for hypoventilation (e.g., chest deformity, coexisting pulmonary or neuromuscular disease, etc.). These patients share many clinical features with patients with OSAS (and many have both diseases), but the OHS is
Table 2. Adjusted neck circumference and clinical probability of OSAS

\begin{tabular}{lc}
\hline If the patient & \\
\hline Is hypertensive & add $4 \mathrm{~cm}$ \\
Is an habitual snorer & add $3 \mathrm{~cm}$ \\
reporting choking or suffocation most nights & add $3 \mathrm{~cm}$ \\
Total & $\ldots \ldots \mathrm{cm}$ \\
\hline Clinical probability & Low \\
\hline Less than $43 \mathrm{~cm}$ & Intermediate \\
From 43 to $48 \mathrm{~cm}$ & High \\
\hline
\end{tabular}

Table 3. Epworth sleepness scale

\begin{tabular}{|c|c|c|c|}
\hline \multicolumn{3}{|c|}{ Condition } & $\begin{array}{c}\text { Chance of } \\
\text { dozing }\end{array}$ \\
\hline \multicolumn{4}{|c|}{ Sitting reading } \\
\hline \multicolumn{4}{|c|}{ Watching TV } \\
\hline \multicolumn{4}{|c|}{ Sitting inactive in a public place (e.g. waiting room, theater) } \\
\hline \multicolumn{4}{|c|}{ As a passenger in a car for 1 hour without stopping } \\
\hline \multicolumn{4}{|c|}{ Laying to rest after lunch if circumstances permit } \\
\hline \multicolumn{4}{|c|}{ Sitting and talking to someone } \\
\hline \multicolumn{4}{|c|}{ Sitting in a quiet place after lunch without alcohol } \\
\hline \multicolumn{4}{|c|}{ In a car stopped for a few minutes due to traffic } \\
\hline & & Results & \\
\hline 0 & No chance of dozing & $0-10$ & Normal \\
\hline 1 & Low chance of dozing & $11-12$ & Borderline \\
\hline 2 & Moderate chance of dozing & $>12$ & Abnormal \\
\hline
\end{tabular}

more severe and is associated with increased morbidity and mortality, usually related to cardiac and respiratory failure. In our experience, in the Obesity Clinic of the Hospital das Clínicas, the measurement of oxygen saturation allows us to identify patients with higher risk of OHS and/or OSAS, being abnormal ( $\mathrm{SpO} 2<95 \%)$ in approximately $33 \%$ of our obese ambulatory patients $\left(\mathrm{BMI}>30 \mathrm{~kg} / \mathrm{m}^{2}\right)$. OHS patients not receiving noninvasive ventilatory support (NIV: continuous positive air pressure CPAP, or oxygen therapy) during treatment have a mortality of $23 \%$ at 18 months and $46 \%$ in seven years, compared to $3 \%$ and $22 \%$ respectively in those receiving NIV support, which should be established preferably before bariatric surgery (34).

The initial respiratory evaluation of patients before bariatric surgery includes, beyond history and detailed physical examination, measurement of adjusted neck circumference (Table 2), ESS (Table 3), chest radiography, and measurement of $\mathrm{SpO}_{2}$. Patients with excessive daytime sleepiness (ESS >10) and/or adjusted neck circumference $>43 \mathrm{~cm}$ ideally should undergo polysom- 
nography, even when the $\mathrm{SpO} 2$ is normal. If it is not possible to perform polysomnography or if OSAS is diagnosed, respiratory therapy with CPAP at night is indicated. Patients with $\mathrm{SpO} 2<95 \%$ and/or bicarbonate in venous blood $>27 \mathrm{mEq} / \mathrm{L}$ (in the absence of an oximeter, assessment of venous bicarbonate levelscan be used instead) should undergo arterial blood gas analysis to assess the $\mathrm{PaCO}_{2}$. If confirmed the diagnosis of OHS, continuous oxygen therapy is indicated. At that time, it is extremely important to rule out the presence of active intrinsic lung disease through medical history, chest radiography, echocardiography, and spirometry. The severity of the nocturnal hypoxemia is a useful tool to suspect OHS when interpreting the polysomnogram as patients with OHS spend more than $50 \%$ of total sleep time with $\mathrm{SpO}_{2}$ below $90 \%$. These patients, as well as smokers, should be referred to a pulmonologist, who will assess the severity of the disease and surgical risk. In this group of patients are those with respiratory disease associated with elevated pulmonary arterial pressure, in which should be evaluated together with the endocrinologist, the potential reduction of pulmonary hypertension with weight loss, to judge whether surgery is feasible for the improvement of the patient. It is mandatory cessation of smoking at least two months before surgery. Likewise, smoking should be avoided after surgery given the increased risk for of poor wound healing and anastomotic ulcer $(31,34)$.

A careful and detailed evaluation of the upper airway of the obese patient is required prior to elective intubation and even mask ventilation can be difficult. The incidence of difficult intubation by anesthetists is around $13 \%$, especially in patients with Mallampati score III and IV. These problems are caused by the presence of fatty deposits in the face, malar region, chest, tongue, and the short neck with excess soft tissue, palate, pharynx and upper and anterior larynx. Furthermore, there may be restriction of mouth opening and limitations of flexion and extension of the cervical spine. Equipment for cricothyroidotomy and transtracheal ventilation should always be available. The examination of these patients should include an analysis of the head and neck region, including flexion, extension and lateral rotation of the neck, jaw mobility and mouth opening, inspection of the oropharynx, teeth and patency of the nostrils. It is essential to enquiry the patient about former difficulties in ventilation or intubation (28).

Gastrointestinal complaints should be evaluated before bariatric surgery with imaging studies, endoscopy, and screening for the presence of Helicobacter pylori. Abdominal ultrasound and a viral hepatitis screen are recommended to evaluate symptomatic biliary disease and if liver function tests are elevated $(8,13)$.

In patients with a history of gout, prophylactic treatment for gouty attacks should be considered before bariatric surgery, because active weight loss has been identified as an important risk factor for hyperuricemia and acute gouty attacks (35).

A psychological assessment is mandatory for all patients before bariatric surgery. Patients should undertake an assessment of their capability to incorporate nutritional and behavioral changes after the operation. If there is an identified or suspected psychiatric disease, or substance abuse, or addiction, a proper mental evaluation with a psychiatrics before the surgical procedure must be done. After surgery, mainly RYGB, high-risk individuals should eliminate alcohol intake because of reduced alcohol metabolism and enhanced risk of alcohol dependence. Every patient should undergo a proper nutritional assessment, including micronutrient measurements, before bariatric procedures. A consultation for postoperative meal initiation and staged meal progression must be conducted by a nutritionist who is familiar with the postoperative bariatric diet. Furthermore, patients should be advised to masticate small bites of food carefully before swallowing, and also follow values of healthy eating, including a minimal protein intake of 1.0 to $1.5 \mathrm{~g} / \mathrm{kg}$ ideal body weight per day, eliminating intense sweets after RYGB to reduce symptoms of the dumping syndrome, as well as after any bariatric technique to decrease energy ingestion $(13,26)$.

Extended-release medications should be avoided; as an alternative, crushed or liquid rapid-release medications should be used to maximize absorption in postoperative phase (13).

Minimal regular nutritional supplementation for patients with RYGB, SG and BPD should contain an adult multivitamin plus mineral supplement (containing folic acid, iron and thiamine) at least $1200 \mathrm{mg}$ of elemental calcium (in diet and if possible as calcium citrate supplement in divided doses, because citrate is less dependent of the acid for its absorption than carbonate), at least 3000 international units daily of vitamin D (or 20000 international units weekly to prevent or minimize secondary hyperparathyroidism), and vitamin B12 (intramuscular, or orally, if determined to be sufficiently absorbed) as required to conserve vitamin 
B12 levels in the normal range (at least above $400 \mathrm{pg} / \mathrm{mL}$ ). Vitamin B12 levels also should be checked in every patient in the baseline and postoperatively annually in those procedures that exclude the lower part of the stomach (e.g., SG, RYGB). Oral supplementation with crystalline vitamin B12 at a dosage of $1000 \mu \mathrm{g}$ daily or more may be used to maintain normal vitamin B12 levels. Some countries have available intranasal and sublingual vitamin B12. We are used to prescribe intramuscular B12 supplementation, $1000 \mu \mathrm{g} /$ month to 5000 $\mu \mathrm{g}$ every 6 months if B12 sufficiency cannot be maintained using oral $(5000 \mu \mathrm{g}$ tablet daily) or intranasal routes (13). Total iron should be at least $45 \mathrm{mg}$ provided by multivitamins and/or additional supplements (In table 4 is displayed the minimal regular nutritional supplementation for patients after RYGB). Minimal daily nutritional supplementation for patients with AGB should be the same, however, without iron and vitamin B12. Liquids should be consumed slowly, if possible at least 30 minutes after meals to avoid gastrointestinal complaints, and in satisfactory volumes to sustain satisfactory hydration (at least 1.5 liters daily) (36).

Levels of homocysteine, red blood cell folate and methylmalonic acid can also be used as biochemical and functional markers to maintain folic acid and vitamin B12 within target ranges. Vitamin D supplementation as high as 6000 IU daily is harmless and obligatory in several post bariatric surgery subjects to reach target levels (13).

Micronutrient deficiencies should be treated with the respective micronutrient $(8,36)$. In cases of severe vitamin D malabsorption, oral doses of vitamin D2 or D3 may need to be as high as 50,000 international units 1 to 3 times weekly to daily and more refractory cases may require simultaneous oral administration of calcitriol (1,25-dihydroxyvitamin D). Assessment should comprise serum parathyroid hormone (PTH), total calcium, phosphorus, 25-hydroxyvitamin $\mathrm{D}$, and 24-hour urine calcium levels (13).

Table 4. Minimal regular nutritional supplement for patients after Rouxen- $Y$ gastric bypass

\begin{tabular}{|c|c|}
\hline Component & Via \\
\hline Multivitamin plus minerals tablets & Oral \\
\hline Calcium citrate $>1,200 \mathrm{mg} /$ day, divided doses & Oral \\
\hline Vitamin D3 > 3000 IU/day, or > 20000 IU/week* & Oral \\
\hline Vitamin B12 5000 ug tablets, or 1000,5000 or 15000 ug vial* & $\begin{array}{c}\text { Oral, or } \\
\text { intramuscular }\end{array}$ \\
\hline Iron (sulfate, fumarate, hydroxide, gluconate) $>45$ mg/day** & Oral \\
\hline
\end{tabular}

In patients who have undertaken RYGB, and BPDs, bone density measurements with use of axial (spine and hip) dual-energy x-ray absorptiometry (DXA) may be indicated to monitor for osteopenia or osteoporosis at baseline and around 2 years. Although new but little available larger machines can accommodate up to $204 \mathrm{~kg}$, forearm bone density measurements remain a reasonable option for preoperative screening and post operative surveillance. Bisphosphonates may be considered in patients with osteoporosis after appropriate treatment with calcium and vitamin D. Concerns generally occur about adequate oral absorption and possible anastomotic ulceration with orally administered bisphosphonates; therefore, intravenously bisphosphonates should be preferred. The recommended dosages of bisphosphonates include zoledronic acid, $5 \mathrm{mg}$ intravenous once a year, or ibandronate, $3 \mathrm{mg}$ intravenous every 3 months. If the concerns above are irrelevant, oral bisphosphonate administration can be delivered (alendronate $70 \mathrm{mg}$ /week; risedronate $35 \mathrm{mg}$ /week or $150 \mathrm{mg} /$ month; or ibandronate $150 \mathrm{mg} /$ month) (13).

Iron levels should be monitored in all bariatric surgery patients and anemia deserves assessment of alimentary insufficiencies, and appropriate causes. Treatment routines include oral ferrous sulfate, fumarate, hydroxide or gluconate to provide up to 150-200 mg of elemental iron daily. Intravenous iron infusion may be needed for patients with severe intolerance to oral iron or refractory deficiency due to severe iron malabsorption (13).

Folic acid supplementation in the dosage of $400 \mu \mathrm{g}$ daily usually is part of the mineral-multivitamin supplementation, but should be administered in all women of reproduction age to diminish the risk of fetal neural tube defect (13).

After malabsorptive procedures such as BPDs, nutritional anemias might comprise deficits in copper, selenium, and zinc. Selenium levels should be monitored in patients with a malabsorptive bariatric surgical procedure who have inexplicable anemia, diarrhea, cardiomyopathy, or bone disease. Screening for zinc deficit should be considered after BPDs and should be consistently supplemented. Zinc deficiency should be considered in patients with hair loss, pica, dysgeusia, or in male patients with hypogonadism or erectile dysfunction. Copper supplementation in the dosage of $2 \mathrm{mg}$ daily should be part of the multivitamin-mineral supplementation. Routine copper screening is not indicated after bariatric surgery but should be appraised in patients with anemia, neutropenia, myeloneuropathy and impaired wound 
healing. In severe deficiency, treatment can be initiated with intravenous copper. Patients being treated for zinc deficit or using supplemental zinc for hair loss should receive $1 \mathrm{mg}$ of copper for each 8 to $15 \mathrm{mg}$ of zinc as zinc replacement can cause copper deficit (13).

Thiamine is part of routine multivitamin supplementation and screening is only necessary in the scenario of post bariatric surgery patients with fast weight loss, prolonged vomiting, alcohol abuse, neuropathy, encephalopathy, or heart failure. Thiamine deficiency (suspected or established), if severe, should be treated with intravenous thiamine, $500 \mathrm{mg}$ daily, for 5 days, followed by $250 \mathrm{mg}$ daily until resolution of symptoms. Less severe cases can be treated with intravenous thiamine, $100 \mathrm{mg}$ daily for 1 or 2 weeks (13).

In patients with type 2 diabetes, fasting blood glucose concentrations and hemoglobin Alc should be determined occasionally. Preprandial, 2-hour postprandial, and bedtime reflectance meter glucose determinations in the home setting should be requested at the discretion of the physician caring for the patient and if symptoms of hypoglycemia occur. In patients with diabetes, the use of insulin secretagogues (sulfonylureas and meglitinides) should be stopped and insulin dosages should be adjusted or discontinued postoperatively to reduce the hazard of hypoglycemia. Metformin may be sustained postoperatively until persistent clinical resolution of diabetes is demonstrated by normalized glycemic goals, when antidiabetic medications should be withheld. Metformin associated to incretin-based therapies should be considered in patients not getting glycemic targets (13).

The requirement of antihypertensive and lipidlowering medications should be periodically assessed. The effect of weight loss on blood pressure and dyslipidemia is variable, and drugs should not be stopped unless clearly indicated (37).

Deep venous thrombosis (DVT) and pulmonary embolism are frightening complications after bariatric surgery. Prophylaxis against DVT is recommended for every patient, including subcutaneously administered unfractionated heparin or low-molecular-weight heparin given within 24 hours after bariatric surgery sequential compression devices and early ambulation. Gastrointestinal bleeding can occur in the lines or stapling or anastomoses being manifested as melena. It is usually self-limited, and it should be evaluated the possibility of stopping the prophylaxis against DVT (13).

Our group some years ago documented that severe obesity is associated with increased TSH levels and sub- clinical hypothyroidism, and that following bariatric surgery and weight loss, TSH levels decrease. In short, obesity corpulence appears to be associated with TSH elevation in the absence of a primary thyroid disease (38).

The regularity and frequency of follow up depends on the bariatric procedure performed and the severity of the co-morbidities. For instance, after AGB, recurrent band adjustments and visits to the dietitian are of imperative importance for maximal weight loss. Significant regain of weight or failure to lose weight due to decreased patient adherence with lifestyle modification, development of maladaptive eating behaviors, or inadequate band restriction. In other patients, without complete resolution of type 2 diabetes, dyslipidemia, or hypertension, continued surveillance and management these conditions should assure frequent follow up (13).

Interventions should contain a multidisciplinary approach, including dietary change, physical activity, behavioral modification with frequent follow up; and the if appropriate, pharmacologic therapy and (if necessary, in selected cases) surgical revision. Routine metabolic and nutritional monitoring is recommended after all bariatric surgical procedures. Visits should be more frequent in the first two years, and can be judiciously less recurrent at the discretion of the physician caring for the patient according to the examination (13).

Patients who have undertaken RYGB, BPD/ Scopinaro, or BPD/DS and who present with postprandial hypoglycaemic symptoms, evidence for lowered blood glucose simultaneous with signs and symptoms should first be advised on dietary changes (low sugar regimens, regular mealtime). Continuous glucose monitoring system can give a clue in patients with questions regarding sporadic hypoglycemia. Sporadic reflectance meter glucose determinations in the home setting should be requested to certificate and these subjects should be submitted to an evaluation to differentiate non insulinoma pancreatogenous hypoglycemia syndrome (NIPHS) from factitious or iatrogenic causes, dumping syndrome, and insulinoma. In these patients, second-line medical therapeutic strategies can be considered, including acarbose, calcium channel antagonists (verapamyl), octreotide and diazoxide $(11,13,39,40)$.

Hygienic plastic and body-contouring operation can be executed after bariatric surgery to handle excess skin that prejudices asepsis, causes distress, and is muti- 
lating. This surgery is best performed after stabilization of the weight (4l).

Reversal of the bariatric surgeries is very rare. In a retrospective review, there were found 13 reversals among 2,825 bariatric surgeries, including primary and revisional operations. The main rationale for reversal of bariatric procedures were intractable vomiting or diarrhea, substance and alcohol abuse, and severe metabolic complications, but reversal could be obviated in about $50 \%$ of patients with patient education and adequate follow up (42).

\section{SURGICAL COMPLICATIONS}

Marginal ulcer at the gastrojejunal anastomosis in RYGB and erosion of the band in the banded RYGB (can cause pain, weight gain or obstruction) are causes of later gastrointestinal bleeding postoperatively. The silicone band of the AGB can move distally, which is called slippage, causing vomiting, dysphagia, heartburn or halitosis. The diagnosis is confirmed by endoscopy or contrast radiography showing a dilated gastric pouch with asymmetric air-fluid level and a diverted band. The band of the banded RYGB can also slide causing stenosis due to be displaced from its usual position or due to be too tight, leading to conditions of difficulty of gastric emptying, vomiting and food intolerance, esophagitis, and dilated pouch. The treatment may be to remove the band or endoscopic dilatation $(13,26)$.

GI barium contrast studies or computed tomography can be indicated to assess suspected anastomotic leaks. Exploratory laparotomy/laparoscopy is warranted if the suspicion for anastomotic leaks is extremely high (e.g., persistent tachycardia, tachypnea, hypoxia, fever, elevated C-reactive protein levels) in spite of a negative study. SG leaks are feared complications due to be leaks of high pressure, taking much longer to close than RYGB leaks, and being causes of prolonged hospitalization, and high morbidity. Overall SG leaks occur at the angle of Hiss, due to excessive narrowing of the gastrectomyat the incisura angularis, which can raise the pressure, initiating the leak $(13,43)$.

Ultrasound is the best feasible method and is conventionally used to assess gallstone formation in the post bariatric operated patient. Ursodeoxycholic acid (300-1200 mg/d) significantly reduces gallstone formation after bariatric surgery. In patients that already have gallbladder disease, with cholecystolithiasis, there is no consensus. Most surgeons prefer to perform the bariatric surgery first, not to increase the surgical time, reducing the risk of complications. Then, after some months, the cholecystectomy is performed in better patient's conditions. Others, depending on the surgical conditions, make the two procedures (bariatric surgery and cholecystectomy) at the same time. There are some who prefer first remove the gallbladder and, in a second time perform the bariatric surgery $(11,44)$.

Obesity can be associated with impairments of cutaneous wound healing, wound failure and fascial dehiscence, and postsurgical complications after open bariatrical operations result in unplanned hospitalizations as well as readmissions. Fortunately, nowadays, most of the surgeries have been performed by through videolaparoscopy so that this complication has been less common (45).

The risk of rhabdomyolysis rises with $\mathrm{BMI}>55-60$ $\mathrm{kg} / \mathrm{m}^{2}$ particularly in extensive and prolonged surgical procedures. The risk of rhabdomyolysis has declined in recent years due to advances in anesthesia, in the degree of muscular relaxation, use of adequate padding at pressure points during bariatric surgery, due to the recommendation of preoperative weight loss in patients at high risk and technical advances that allowed reduction of surgical time. Nevertheless, screening creatine kinase levels are justified in these higher risk individuals, urine output should be supervised, and adequate hydration is warranted (11).

Likewise, preoperative weight loss can reduce liver volume improving technical aspects of the operation in patients with an enlarged fatty liver, and also be useful to improve comorbidities, such as reach reasonable preoperative glycemic targets in uncontrolled diabetic patients (13).

If the patient has gastrointestinal symptoms suggestive of stricture or foreign body (e.g., suture, staple), endoscopy is the chosen technique because it can be diagnostic and also therapeutic (dilation of the stricture and foreign body removal) (13).

Non steroidal antiinflammatory medications should be absolutely avoided after bariatric surgery, because they have been associated with increase in ulcerations and/or perforations in the gastrojejunal anastomosis and substitute pain drugs should be used. In the presence of anastomotic ulcers, they should be treated with $\mathrm{H} 2$ receptor blockers, proton pump inhibitors, sucralfate, and if $H$. pylori is identified, triple therapy to include antibiotics, bismuth, and proton pump inhibitors (37). 
Symptomatic hernias that supervene after bariatric surgery need rapid surgical assessment. Subjects with abrupt onset, severe cramping periumbilical discomfort or repeated episodes of abdominal pain after RYGB or BPDs surgeries must be evaluated with an abdominal CT scan to exclude the complication of an internal hernia with a bowel obstruction. Exploratory laparotomy or laparoscopy is indicated in patients who are suspected of having an internal hernia since this potentially life-threatening complication can be missed with upper gastrointestinal $\mathrm{x}$-ray studies (13).

Enteric hyperoxaluria and kidney stones of calcium oxalate development can occur after RYGB and BPDs and are linked to fat malabsorption, which fixes to calcium, increasing free oxalate that is absorbed in the gut. Therapeutic approaches to manage hyperoxaluria include sufficient hydration, decreasing oxalate dietary consumption, and calcium citrate supplementation (13).

The mortality associated with bariatric surgery can be higher in patients with BMI above $60 \mathrm{~kg} / \mathrm{m}^{2}$, with morbid obesity for more than five years, over 40 years old, with more than three significant comorbidities such as diabetes, sleep apnea, lung and heart diseases, and Classification of the American Society of Anesthesiology (ASA) 3 and 4 (46).

Nonetheless, RYGB has been improved and amended in the course of time, making it safer than it was 20 or 30 years ago, thus, reducing operative mortality that is now lower for laparoscopic RYGB than for a cholecystectomy, being lower than $0.2 \%$. The establishment of centers of excellence in bariatric surgery was associated with lower rates of reoperations and complications. Such policies, associated to laparoscopic and robotic surgery, which provide more accuracy, better training and preparation of the staff and surgeons may become a powerful tool to improve surgical safety and quality $(47,48)$.

In conclusion, bariatric surgery is the most effective method of treatment of the morbidly obese patients, with robust evidence of reduction in the incidence of new comorbidities, in the prevalence of pre-existing disorders, as well as in mortality, provided that the procedure is followed by an interdisciplinary experienced staff and in a qualified obesity management center.

Acknowledgements: the author thanks Dr. Denis Pajeckifor his assistance regarding reviewing and suggestions and Tadeu Mancini for the graphic design of the bariatric operations and the endoscopic device.

Disclosure: no potential conflict of interest relevant to this article was reported.

\section{REFERENCES}

1. Office of the Surgeon General (US); Office of Disease Prevention and Health Promotion (US); Centers for Disease Control and Prevention (US); National Institutes of Health (US). The Surgeon General's Call To Action To Prevent and Decrease Overweight and Obesity. Rockville (MD): Office of the Surgeon General (US); 2001. Section 1: Overweight and Obesity as Public Health Problems in America. Available at: Accessed on: Dec, 25, 2013.

2. Kelly T, Yang W, Chen CS, Reynolds K, He J. Global burden of obesity in 2005 and projections to 2030. Int J Obes (Lond). 2008;32(9):1431-7.

3. Berrington de GA, Hartge P, Cerhan JR, Flint AJ, Hannan L, Maclnnis RJ, et al. Body-mass index and mortality among 1.46 million white adults. N Engl J Med. 2010;363(23):2211-9.

4. Flegal KM, Kit BK, Orpana H, Graubard BI. Association of all-cause mortality with overweight and obesity using standard body mass index categories: a systematic review and meta-analysis. JAMA. 2013;309(1):71-82.

5. Colles SL, Dixon JB, O'Brien PE. Loss of control is central to psychological disturbance associated with binge eating disorder. Obesity (Silver Spring). 2008;16(3):608-14.

6. Fontaine KR, Redden DT, Wang C, Westfall AO, Allison DB. Years of life lost due to obesity. JAMA. 2003;289(2):187-93.

7. Sjostrom L. Review of the key results from the Swedish Obese Subjects (SOS) trial - A prospective controlled intervention study of bariatric surgery. J Intern Med. 2013;273(3):219-34.

8. Padwal R, Klarenbach S, Wiebe N, Birch D, Karmali S, Manns B, et al. Bariatric surgery: a systematic review and network metaanalysis of randomized trials. Obes Rev. 2011;12(8):602-21.

9. Christou NV, Sampalis JS, Liberman M, Look D, Auger S, McLean AP, et al. Surgery decreases long-term mortality, morbidity, and health care use in morbidly obese patients. Ann Surg. 2004;240(3):416-23.

10. Hofso D, Nordstrand N, Johnson LK, KarlsenTI, Hager H, Jenssen $T$, et al. Obesity-related cardiovascular risk factors after weight loss: a clinical trial comparing gastric bypass surgery and intensive lifestyle intervention. Eur J Endocrinol. 2010;163(5):735-45.

11. Fried M, Yumuk V, Oppert JM, Scopinaro N, Torres A, Weiner R, et al.; International Federation for Surgery of Obesity and Metabolic Disorders-European Chapter (IFSO-EC); European Association for the Study of Obesity (EASO); European Association for the Study of Obesity Obesity Management Task Force (EASO OMTF). Interdisciplinary European guidelines on metabolic and bariatric surgery. Obes Surg. 2014;24(1):42-55.

12. Flum DR, Dellinger EP. Impact of gastric bypass operation on survival: a population-based analysis. J Am Coll Surg. 2004;199(4):543-51.

13. Mechanick JI, Youdim A, Jones DB, Garvey WT, Hurley DL, McMahon MM, et al. Clinical practice guidelines for the perioperative nutritional, metabolic, and nonsurgical support of the bariatric surgery patient--2013 update: cosponsored by American Association of Clinical Endocrinologists, The Obesity Society, and American Society for Metabolic \& Bariatric Surgery. Obesity (Silver Spring). 2013;21 Suppl 1:S1-27.

14. Cummings DE, Cohen RV. Beyond BMl: the need for new guidelines governing the use of bariatric and metabolic surgery. Lancet Diabetes Endocrinol. 2014;2(2):175-81.

15. Portaria $n^{\circ} 424$ e 425 de 19/03/2013, Diário Oficial da União MdSdB (2013).

16. Ray EC, Nickels MW, Sayeed S, Sax HC. Predicting success after gastric bypass: the role of psychosocial and behavioral factors. Surgery. 2003;134(4):555-63.

17. Segal A, Kinoshita KD, Larino MA. Post-surgical refusal to eat: anorexia nervosa, bulimia nervosa or a new eating disorder? A case series. Obes Surg. 2004;14(3):353-60. 
18. Romero F, Nicolau J, Flores L, Casamitjana R, Ibarzabal A, Lacy $A$, et al. Comparable early changes in gastrointestinal hormones after sleeve gastrectomy and Roux-En-Y gastric bypass surgery for morbidly obese type 2 diabetic subjects. Surg Endosc. 2012;26(8):2231-9.

19. Stival A, Padoin AV, Lacombe A, de Paula AL, Geloneze Neto B, Schiavon CA, et al. Estado Atual da Cirurgia Metabólica. In: Mancini MC, Geloneze B, Salles JEN, de Lima JG, Carra MK, editors. Tratado de Obesidade. 1. ed. Itapevi SP: GEN Grupo Editorial Nacional Guanabara Koogan; 2010. p. 683-93.

20. Mathus-Vliegen EM. Intragastric balloon treatment for obesity: what does it really offer? Dig Dis. 2008;26(1):40-4.

21. de Moura EG, Martins BC, Lopes GS, Orso IR, de Oliveira SL, Galvao Neto MP, et al. Metabolic improvements in obese type 2 diabetes subjects implanted for 1 year with an endoscopically deployed duodenal-jejunal bypass liner. Diabetes Technol Ther. 2012;14(2):183-9.

22. de Moura EG, Orso IR, Martins BC, Lopes GS, de Oliveira SL, Galvao-Neto MP, et al. Improvement of insulin resistance and reduction of cardiovascular risk among obese patients with type 2 diabetes with the duodenojejunal bypass liner. Obes Surg. 2011;21(7):941-7.

23. Arterburn D, Bogart A, Coleman KJ, Haneuse S, Selby JV, Sherwood NE, et al. Comparative effectiveness of bariatric surgery vs. nonsurgical treatment of type 2 diabetes among severely obese adults. Obes Res Clin Pract. 2013;7(4):e258-68.

24. Arterburn DE, Bogart A, Sherwood NE, Sidney S, Coleman KJ, Haneuse $S$, et al. A multisite study of long-term remission and relapse of type 2 diabetes mellitus following gastric bypass. Obes Surg. 2013;23(1):93-102.

25. Deitel M. Update: Why diabetes does not resolve in some patients after bariatric surgery. Obes Surg. 2011;21(6):794-6.

26. Guelinckx I, Devlieger R, Vansant G. Reproductive outcome after bariatric surgery: a critical review. Hum Reprod Update. 2009;15(2):189-201.

27. Fleisher LA, Beckman JA, Brown KA, Calkins H, Chaikof EL, Fleischmann KE, et al. ACC/AHA 2007 Guidelines on Perioperative Cardiovascular Evaluation and Care for Noncardiac Surgery: Executive Summary: A Report of the American College of Cardiology/American Heart Association Task Force on Practice Guidelines (Writing Committee to Revise the 2002 Guidelines on Perioperative Cardiovascular Evaluation for Noncardiac Surgery) Developed in Collaboration With the American Society of Echocardiography, American Society of Nuclear Cardiology, Heart Rhythm Society, Society of Cardiovascular Anesthesiologists, Society for Cardiovascular Angiography and Interventions, Society for Vascular Medicine and Biology, and Society for Vascular Surgery. J Am Coll Cardiol 2007;50(17):1707-32.

28. Mancini MC. Obstáculos diagnósticos e desafios terapêuticos no paciente obeso. Arq Bras Endocrinol Metab. 2001;45(6):584-608.

29. Fleisher LA, Beckman JA, Brown KA, Calkins H, Chaikof EL, Fleischmann KE, et al. 2009 ACCF/AHA focused update on perioperative beta blockade incorporated into the ACC/AHA 2007 guidelines on perioperative cardiovascular evaluation and care for noncardiac surgery. J Am Coll Cardiol. 2009;54(22):e13-e118.

30. Garimella S, Longaker RA, Stoddard MF. Safety of transesophageal echocardiography in patients who are obese. J Am Soc Echocardiogr 2002;15(11):1396-400.
31. de Sousa AG, Cercato C, Mancini MC, Halpern A. Obesity and obstructive sleep apnea-hypopnea syndrome. Obes Rev. 2008;9(4):340-54.

32. Johns MW. A new method for measuring daytime sleepiness: the Epworth sleepiness scale. Sleep 1991;14(6):540-5.

33. Netzer NC, Stoohs RA, Netzer CM, Clark K, Strohl KP. Using the Berlin Questionnaire to identify patients at risk for the sleep apnea syndrome. Ann Intern Med. 1999;131(7):485-91.

34. Budweiser S, Riedl SG, Jorres RA, Heinemann F, Pfeifer M. Mortality and prognostic factors in patients with obesity-hypoventilation syndrome undergoing noninvasive ventilation. J Intern Med 2007;261(4):375-83.

35. Friedman JE, Dallal RM, Lord JL. Gouty attacks occur frequently in postoperative gastric bypass patients. Surg Obes Relat Dis. 2008;4(1):11-3.

36. Alvarez-Leite JI. Nutrient deficiencies secondary to bariatric surgery. Curr Opin Clin Nutr Metab Care. 2004;7(5):569-75.

37. Miller AD, Smith KM. Medication and nutrient administration considerations after bariatric surgery. Am J Health Syst Pharm. 2006;63(19):1852-7.

38. Moulin de Moraes CM, Mancini MC, de Melo ME, Figueiredo DA, Villares SM, Rascovski A, et al. Prevalence of subclinical hypothyroidism in a morbidly obese population and improvement after weight loss induced by Roux-en-Y gastric bypass. Obes Surg. 2005;15(9):1287-91.

39. Moreira RO, Moreira RB, Machado NA, Goncalves TB, Coutinho WF. Post-prandial hypoglycemia after bariatric surgery: pharmacological treatment with verapamil and acarbose. Obes Surg. 2008;18(12):1618-21.

40. Vidal J, Nicolau J, Romero F, Casamitjana R, Momblan D, Conget I, et al. Long-term effects of Roux-en-Y gastric bypass surgery on plasma glucagon-like peptide-1 and islet function in morbidly obese subjects. J Clin Endocrinol Metab. 2009;94(3):884-91.

41. Hasanbegovic E, Sorensen JA. Complications following body contouring surgery after massive weight loss: a meta-analysis. J Plast Reconstr Aesthet Surg. 2014;67(3):295-301.

42. Brolin RE, Asad M. Rationale for reversal of failed bariatric operations. Surg Obes Relat Dis. 2009;5(6):673-6.

43. Sarkhosh K, Birch DW, Sharma A, Karmali S. Complications associated with laparoscopic sleeve gastrectomy for morbid obesity: a surgeon's guide. Can J Surg. 2013;56(5):347-52.

44. Fuller W, Rasmussen JJ, Ghosh J, Ali MR. Is routine cholecystectomy indicated for asymptomatic cholelithiasis in patients undergoing gastric bypass? Obes Surg. 2007;17(6):747-51.

45. Pierpont YN, Dinh TP, Salas RE, Johnson EL, Wright TG, Robson $M C$, et al. Obesity and surgical wound healing: a current review. ISRN Obes. 2014;638936.

46. Martins-Filho ED, Katz L, Amorim M, Ferraz AA, Ferraz EM. Prediction of severe complications and death in superobese patients undergoing open gastric bypass with the Recife Score. Arq Gastroenterol. 2011;48(1):8-14.

47. Flum DR, Belle SH, King WC, Wahed AS, Berk P, Chapman W, et al. Perioperative safety in the longitudinal assessment of bariatric surgery. N Engl J Med. 2009;361(5):445-54.

48. Kwon S, Wang B, Wong E, Alfonso-Cristancho R, Sullivan SD, Flum DR. The impact of accreditation on safety and cost of bariatric surgery. Surg Obes Relat Dis. 2013;9(5):617-22. 